\title{
Hereditary and non-hereditary etiologies associated with extensive brain calcification: case series
}

\author{
András Salamon ${ }^{1} \cdot$ Dénes Zádori $^{1}$ - Anikó Ujfalusi ${ }^{2}$ - László Szpisjak ${ }^{1} \cdot$ Melinda Lukács $^{1} \cdot$ Brigitta Bihari $^{3}$. \\ Noémi Szépfalusi ${ }^{1}$. Viola Luca Németh ${ }^{1}$ • Zoltán Maróti ${ }^{4}$ • Emese Horváth ${ }^{5} \cdot$ István Balogh $^{2} \cdot$ Csaba Bereczki $^{4}$. \\ Péter Klivényi ${ }^{1} \cdot$ Tibor Kalmár $^{4}$ (D)
}

Received: 23 February 2021 / Accepted: 1 July 2021 / Published online: 21 July 2021

(C) The Author(s), under exclusive licence to Springer Science+Business Media, LLC, part of Springer Nature 2021

\begin{abstract}
Cerebral calcification may be caused by several potentially treatable conditions, however, in most cases it does not receive special attention in clinical practice. From the point of view of etiology, the diseases associated with cerebral calcification can be divided into two main groups: idiopathic (mostly incurable) and secondary (potentially treatable). The first group includes mainly the hereditary diseases identified before 2021 (primary familial brain calcification subtypes, previously known as Fahr's disease or Fahr's syndrome). In contrast, the second group includes diseases with cerebral calcification that develop generally as a consequence of metabolic/endocrine/autoimmune abnormalities. The aim of our research was to present hereditary and non-hereditary etiologies associated with extensive brain calcification. We compare the detailed clinical, radiological and laboratory results of 6 patients with prominent cerebral calcification identified in our clinic in the last 3 years (idiopathic and secondary etiologies as well). Our research draws attention to the complexity of the etiologies in the context of cerebral calcification. We recommend, beside NGS-based sequence analyses, the application of array comparative genomic hybridization as well, to identify potential genetic etiologies associated with brain calcification.
\end{abstract}

Keywords Fahr's syndrome · Genetic · Idiopathic basal ganglia calcification · Primary familial brain calcification · Brain calcification $\cdot$ Mosaicism

András Salamon and Dénes Zádori contributed equally to this work.

Tibor Kalmár

kalmar.tibor@med.u-szeged.hu

1 Department of Neurology, Faculty of Medicine, Albert Szent-Györgyi Clinical Center, University of Szeged, Szeged, Hungary

2 Division of Clinical Genetics, Department of Laboratory of Medicine, Faculty of Medicine, University of Debrecen, Debrecen, Hungary

3 Department of Neurology, Békés County, Orosháza, Hungary

4 Department of Pediatrics, Faculty of Medicine, Albert Szent-Györgyi Clinical Center, University of Szeged, Korányi fasor 14-15, Szeged H-6725, Hungary

5 Department of Medical Genetics, Faculty of Medicine, Albert Szent-Györgyi Clinical Center, University of Szeged,

Szeged, Hungary

\section{Introduction}

Central nervous system calcification may be associated with several different underlying etiologies (Batla et al. 2017; Donzuso et al. 2019; Saleem et al. 2013; Westenberger et al. 2019). However, the clarification of the underlying diseases is often neglected in the daily clinical practice, even though up to $20 \%$ of the head CT scans in the elderly population reveal some degree of brain calcification (Yamada et al. 2013). There have been several attempts to date to classify the brain calcifications, based on location, etiology, and symptomatology (Oliveira et al. 2013; Savino et al. 2016). Manyam (2005) proposed the following classification on anatomical basis: (1) strio-pallido-dentato calcinosis, (2) bilateral strio-pallidal calcinosis and (3) bilateral cerebellar calcification. The use of this classification is complicated by the fact that there is no strong correlation between the localization of calcification and the underlying etiology. From this perspective the main groups are the followings: (1) physiologic/age-related, (2) vascular, (3) neoplastic, (4) infectious, (5) metabolic/endocrine, (6) 
inflammatory/autoimmune, (7) genetically determined disorders and (8) toxic diseases (Kiroğlu et al. 2010; Saade et al. 2019; Saleem et al. 2013; Taborda et al. 2017) (Table 1). A serious shortcoming of the above etiological classification is that individual diseases can even be classified into several groups. Depending on the localization and the etiology of brain calcification, a wide range of potential neurological (e.g. movement disorder), psychiatric and musculoskeletal symptoms may appear, however, these symptoms are not really helpful during the differential diagnostic process (Batla et al. 2017; Kostić and Petrović 2017). From the etiological perspective, the greatest challenge in adult neurological patient care is to differentiate between endocrine/metabolic (potentially treatable) and the genetically determined (mostly incurable) forms of brain calcification. Therefore, diagnostic algorithms have been presented to help in distinguishing (Bonazza et al. 2011; Saleem et al. 2013).

Extended genetic studies revealed new genes responsible for primary familial brain calcification (previously known as idiopathic basal ganglia calcification/IBGC/ or Fahr's disease or Fahr's syndrome) (Table 2) (Batla et al. 2017; Westenberger et al. 2019). These are mostly autosomal dominantly inherited (e.g. SLC2OA2), however, some types show autosomal recessive inheritance (e.g. MYORG).

The aim of this case series is to compare the clinical, laboratory, and radiological features of hereditary and nonhereditary etiologies identified in association with extensive cerebral calcification.

\section{Case reports}

\section{Case 1 - Mos 46,XY,der(11)t(X;11)(p21.1;q14.2)[152] [46,XY[48]}

The 57-year-old male patient was admitted to the outpatient clinic due to severe gait disturbance, swallowing difficulty, and speech disorder. It should be noted from the previous medical history of the patient that he suffered from an ischemic stroke in the territory of the right middle cerebral artery 2 years prior to admission. The following neurological symptoms were observed during the detailed examination: upward gaze palsy, abnormal saccadic eye movements, severe dysarthria and dysphagia, prominent four-limb ataxia, severe trunk ataxia, tremor (resting and postural), urinary incontinence (Supplementary video 1). No signs of dysmorphia were observed on the patient. The performed detailed laboratory tests demonstrated normal results except for slightly elevated serum alkaline phosphatase and urine calcium levels (Table 3). Routine electroencephalography (EEG) found no epileptiform abnormalities, however, focal slowing in the right frontal-, temporal- and left frontal regions was detected as well. The Addenbrooke's cognitive examination (ACE) detected a mild cognitive decline (76/100), principally the anterograde memory and the attention-related functions were involved. Extensive intracerebral calcification was revealed by head CT scan (Fig. 1 - Case 1). It showed primarily the involvement of the basal ganglia, cerebellum, deep white matter, and
Table 1 Etiologies of brain calcification (Based on the following articles: Kıroğlu et al. 2010; Saade et al. 2019; Saleem et al. 2013, Taborda et al., 2017) (Abbreviations: ERCC8 - excision repair crosscomplementing, group 8; GNAQ - guanine nucleotide-binding protein, Q polypeptide; GNAS - GNAS complex locus; HIV - human immunodeficiency virus; JAM2 - junctional adhesion molecule 2; MYORG myogenesis-regulating glycosidase; $N F 1$ - neurofibromin $1 ; N F 2$ - neurofibromin 2; $P D G F B$ - platelet-derived growth factor, beta polypeptide; $P D G F R B$ - platelet-derived growth factor receptor, beta; $P T C H 2$ patched 2; SLC2OA2 - solute carrier family 20 (phosphate transporter), member 2; STX16 - syntaxin 16; TORCH - toxoplasmosis, other agents, rubella, cytomegalovirus, herpes simplex; TREX1-3-prime repair exonuclease 1; TSC1 - TSC1 gene; TSC2 - TSC2 gene; XPR1 - xenotropic and polytropic retrovirus receptor)

\section{Etiology group Main subtypes}

(1) Physiologic/age-related

(2) Vascular

(3) Neoplastic

(4) Infectious

(5) Metabolic/endocrine

(6) Inflammatory/autoimmune disorders

(7) Genetically determined disorders

(8) Toxic diseases

Habenular-, pineal-, falcial-, dural-, tentorial-, choroidal- and bilateral basal ganglia calcification

Vasculitis (chronic), arteriosclerosis (primary), arteriovenous- or cavernomatous malformation, aneurysms

Intraaxial (e.g. astrocytoma, oligodendroglioma, ganglioglioma, medulloblastoma, metastasis), extraaxial (e.g. meningioma, craniopharyngioma, pineal tumor, germ cell line tumor) and intraventricular (ependymoma) neoplasms

TORCH, congenital Zika infection, HIV encephalitis, neurocysticercosis, brucellosis, Cryptococcus neoformans infection

Hypothyroidism, hypoparathyroidism (idiopathic, secondary (e.g., postthyroidectomy), pseudo-, pseudo-pseudo), hyperparathyroidism

Systemic lupus erythematosus, cerebral sarcoidosis

SLC20A2, PDGFRB, PDGFB, XPR1, MYORG, JAM2, STX16, GNAS, PTCH2, ERCC8, TREX1, TSC1, TSC2, GNAQ, NF1, $N F 2,6 \mathrm{p} 25$ deletion syndrome

Lead or carbon monoxide poisoning 
Table 2 Genetic subtypes of primary familial brain calcification (Abbreviations: $\mathrm{AD}$ - autosomal dominant; $\mathrm{AR}$ - autosomal recessive; BBB - blood brain barrier; JAM2 - junctional adhesion molecule 2; $M Y O R G$ - myogenesis-regulating glycosidase; N.D. - no data; $P D G F B$
- platelet-derived growth factor, beta polypeptide; PDGFRB - plateletderived growth factor receptor, beta; PFBC - primary familial brain calcification; SLC2OA2 - solute carrier family 20 (phosphate transporter), member 2; XPR1 - xenotropic and polytropic retrovirus receptor)

\begin{tabular}{|c|c|c|c|c|c|c|}
\hline Gene [MIM] & Location & Inheritance & Function & Disease name [MIM] & $\begin{array}{l}\text { Red flag } \\
\text { clinical } \\
\text { symptom } \\
\text { (Batla et al. } \\
\text { 2017) }\end{array}$ & Reference \\
\hline SLC20A2 [158378] & $8 p 11.21$ & $\mathrm{AD}$ & $\begin{array}{l}\text { Inorganic phosphate } \\
\text { transporter type III }\end{array}$ & $\begin{array}{l}\text { PFBC-SLC20A2 } \\
\text { (Idiopathic basal } \\
\text { ganglia calcification } \\
\text { 1) }[213600]\end{array}$ & Parkinsonism & Wang et al. 2012 \\
\hline$P D G F R B[173410]$ & $5 q 32$ & $\mathrm{AD}$ & BBB integrity & $\begin{array}{l}\text { PFBC-PDGFRB } \\
\text { (Idiopathic basal } \\
\text { ganglia calcification } \\
\text { 4) [615007] }\end{array}$ & N.D. & Nicolas et al. 2013b \\
\hline$P D G F B$ [190040] & $22 \mathrm{q} 13.1$ & $\mathrm{AD}$ & $\begin{array}{l}\text { Pericyte regulation, } \\
\text { BBB integrity }\end{array}$ & $\begin{array}{l}\text { PFBC-PDGFB } \\
\text { (Idiopathic basal } \\
\text { ganglia calcification } \\
\text { 5) [615483] }\end{array}$ & Headache & Keller et al. 2013 \\
\hline XPR1 [605237] & $1 \mathrm{q} 25.3$ & $\mathrm{AD}$ & $\begin{array}{l}\text { Inorganic phosphate } \\
\text { transporter type III }\end{array}$ & $\begin{array}{l}\text { PFBC-XPR1 } \\
\text { (Idiopathic basal } \\
\text { ganglia calcification } \\
\text { 6) }[616413]\end{array}$ & N.D. & Legati et al. 2015 \\
\hline MYORG [618255] & $9 \mathrm{p} 13.3$ & $\mathrm{AR}$ & $\begin{array}{l}\text { Ion homeostasis } \\
\text { regulation via the } \\
\text { glycosidase domain }\end{array}$ & $\begin{array}{l}\text { PFBC-MYORG } \\
\text { (Idiopathic basal } \\
\text { ganglia calcification } \\
\text { 7) [618317] }\end{array}$ & Dysarthria & Bauer et al. 2019 \\
\hline JAM2 [606870] & $21 \mathrm{q} 21.3$ & $\mathrm{AR}$ & $\begin{array}{l}\text { Cell-cell adhesion, } \\
\text { maintaining the } \\
\text { integrity of } \\
\text { neurovascular unit }\end{array}$ & $\begin{array}{l}\text { PFBC-JAM2 } \\
\text { (Idiopathic basal } \\
\text { ganglia calcification } \\
\text { 8) [618824] }\end{array}$ & N.D. & Cen et al. 2020 \\
\hline
\end{tabular}

brainstem (pons). Abdominal MRI detected cavernomatous hemangiomas, which may partly explain the mild elevation of alkaline phosphatase. Chest X-ray confirmed pneumonia, which was presumably associated with elevated urinary calcium level. Extensive genetic studies (clinical exome sequencing searching for the known genes behind idiopathic basal ganglia calcification, then G-banded karyotyping, array comparative genomic hybridization $(\mathrm{aCGH})$, fluorescence in situ hybridization and multiplex ligation-dependent probe amplification) were performed on DNA isolated from blood and oral mucosa cells, respectively. Clinical exome sequencing indicated a deletion in chromosome 11, which prompted aCGH analyses. A mosaic form of presumed unbalanced translocation between chromosome $\mathrm{X}$ and 11 was detected. The karyotype of the patient was the following: mos 46,XY,der(11)t(X;11)(p21.1;q14.2)[152]/46,XY[48] that resulted in Xpter $\rightarrow 21.1$ duplication and 11qter $\rightarrow 14.2$ deletion. The gene content of the affected chromosomal regions was determined by UCSC Genome Browser, Ensembl BioMart and OMIM databases and is included in the Supplementary file 1 . Given the newly identified genetic abnormality, it was not possible to initiate specific treatment in the absence of scientific data. The patient has 5 asymptomatic children (3 daughters and 2 sons) in whom the chromosomal rearrangement was not found (only blood samples were analyzed; no calcification was observed in the performed skull CT scans) (Supplementary file 2). The father of the proband died of a lung neoplastic process; however, he did not suffer from a similar disease. Her mother was not facilitated to genetic testing due to her old age ( 82 years).

\section{Case 2 - SLC2OA2}

The 68 years old female patient was admitted to our clinic with prominent articulation difficulty and gait abnormality. Her symptoms appeared first at the age of 42 , and then progressed gradually until she was only able to walk safely with a rollator. The major features demonstrated by neurological examination of the patient (Supplementary video 2) were muscle hypotonia and mainly left-sided bradykinesia. Choreiform dyskinesis was observed in the right upper limb. Her gait was unstable lacking the synkinesis of upper limbs 


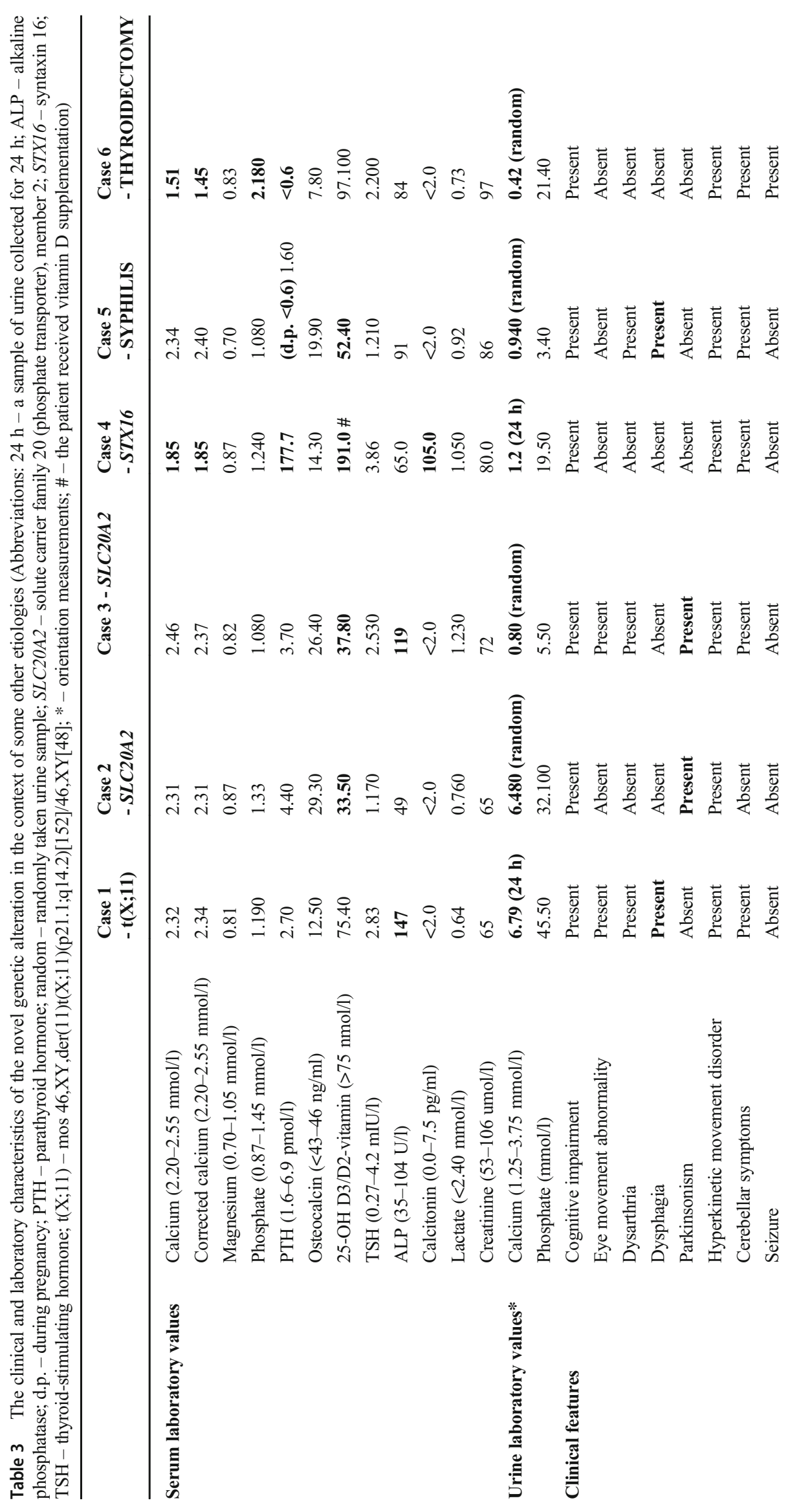



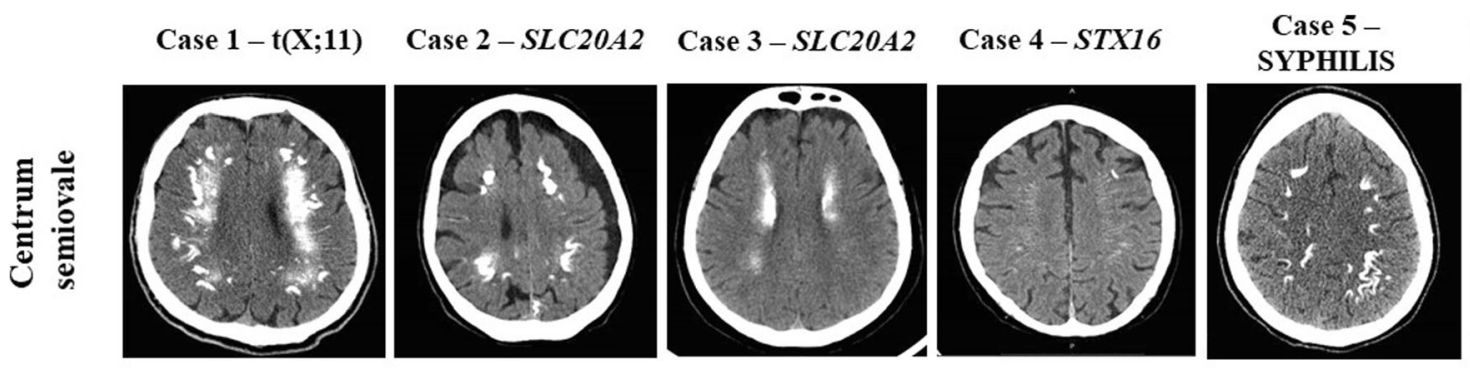

Case 6 - THYROIDECTOMY
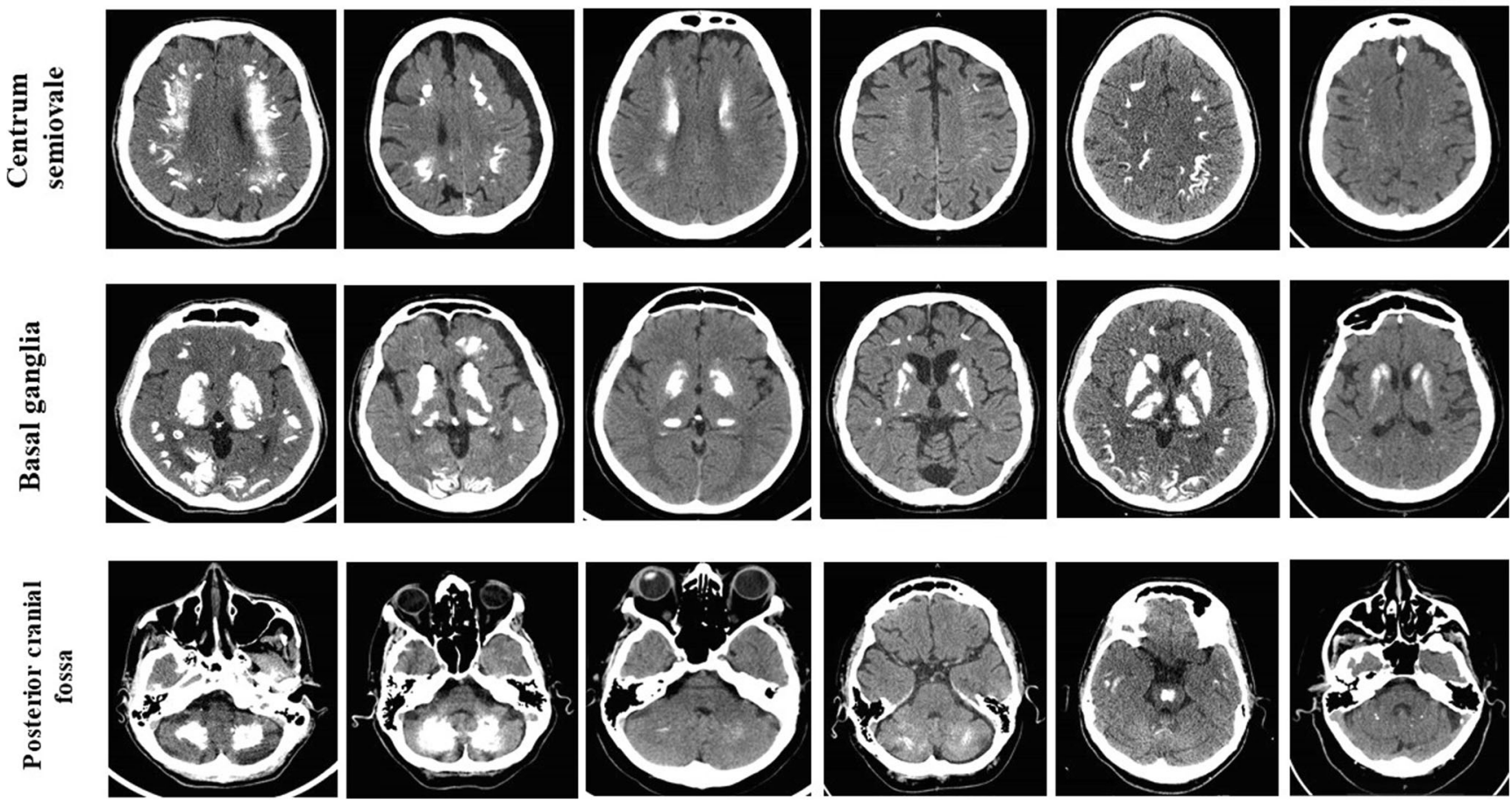

Fig. 1 Head CT images (3 sections: centrum semiovale, basal ganglia, posterior fossa) of the probands (Abbreviation: $1-6-$ the number of the case; SLC2OA2 - solute carrier family 20 (phosphate transporter),

m e mber $2 ; S T X 16$

syntaxin $16 ; \mathrm{t}(\mathrm{X} ; 11)-\operatorname{mos}$ 46,XY,der(11)t(X;11)(p21.1;q14.2)[152]/46,XY[48])

and turning from 6 steps. No other pathological abnormalities other than low 25-OH D3/D2-vitamin levels were detected in the performed detailed laboratory tests (Table 3 ). The routine EEG showed normal brain activity without the evidence of epileptic discharges. The neuropsychological assessment revealed the signs of mild cognitive impairment (ACE: 81/100 points). In the background of this deterioration, working memory and executive dysfunction were identified. Regarding attention-related tasks, a slowing was detected as well. The performed head CT scan showed an extensive symmetrical cerebral calcification with the involvement of basal ganglia, cerebellum and deep white matter (Fig. 1 - Case 2). The performed NGS-based genetic test (clinical exome sequencing and deletion/duplication analysis) revealed a variant of unknown significance (class 3; PolyPhen: probably damaging; Align-GVGD: C0; SIFT: deleterious; MutationTaster: disease causing) in heterozygous state in the SLC2OA2 gene (c.1535G > A; p.Gly512Asp). The detected heterozygous mutation affecting a single nucleotide in SLC2OA2 gene is very rare and was not previously described in 360 Hungarian control samples or in the gnomAD, ClinVar and HGMD databases, which supported the clinical diagnosis. In view of the patient's parkinsonism, we tried rasagiline, levodopa + benserazide and amantadine sulphate treatments, without marked clinical benefit. The proband has only one son (asymptomatic), whose head CT scan did not show intracranial calcification, although he had reached the predilection age (Supplementary file 2). He is not carrier for his mother's SLC2OA2 mutation.

\section{Case 3 - SLC20A2}

A 57-year-old female patient was referred to our clinic with the followings. The patient noticed that her right hand was shaking at rest and she was unable to express herself periodically for the last two months. The patient was undergoing psychiatric care due to depression. The following abnormalities were observed in the neurological status of the patient: psychomotor slowness, cognitive deficit symptoms, square wave jerks and gaze-evoked nystagmus, dysarthria, cerebellar symptoms (dysmetria on the right hand, dysdiadochokinesis, intentional tremor), postural and resting tremor, bradykinesia predominantly at the right side, antalgic gait, absent synkinesis in the right side, tactile hypesthesia in the right body side (Supplementary video 3). The laboratory tests delineated no abnormalities except for low vitamin D and slightly elevated alkaline phosphatase levels (Table 3 ). The result of routine EEG was normal. The conducted neuropsychological assessment revealed signs of psychomotor slowness and lower working memory capacity. The previously performed head CT scan confirmed extensive periventricular, basal ganglia, and cerebellar calcification (Fig. 1 - Case 3). The genetic 
analysis (bidirectional sequencing of the 4 most commonly involved genes (SLC20A2, PDGFB, PDGFRB and XPR1)) detected a known pathogenic mutation in heterozygous state in the $S L C 20 A 2$ gene (c.82G > A, p.Asp28Asn) (Chen et al. 2013). The detected heterozygous mutation affecting a single nucleotide in SLC20A2 gene is very rare and was not previously described in 360 Hungarian control samples or in the gnomAD databases. It is classified as "likely pathogenic idiopathic basal ganglia calcification type 1" according to the ClinVar and HGMD databases. In the treatment of the patient, the primary goal was to manage the psychiatric symptoms, therefore venlafaxine, clonazepam and quetiapine drugs were applied. During the segregation analysis of the family, we also found the mutation in the so far asymptomatic brother of the proband (receiving anticoagulant therapy for deep vein thrombosis), which correlated with the positive head CT result (Supplementary file 2).

\section{Case 4 - STX16}

The 47-year-old male patient was admitted to our clinic with the history of progressive, pronounced gait disorder for 2 years. He also fell several times in the year before his admission and suffered from a fracture of right wrist in connection with one such fall. Detailed neurological examination detected severe cerebellar symptoms (four-limb ataxia, dysdiadochokinesis, disruption of alternating movements, dysarthria) as well as bilateral pyramidal signs (Supplementary video 4). There were abnormalities in laboratory results consistent with secondary hyperparathyroidism (Table 3). The routine EEG did not detect epileptiform dysfunction; however, it showed a slow wave activity in the right occipital region. The neuropsychological assessment raised the possibility of major neurocognitive disorder (ACE: 55/ 100 points). A marked decrease was observed in the tasks examining attention- and memory- and language-related functions. The head CT scan showed pronounced bilateral basal ganglia, cerebellar and brainstem calcification (Fig. 1 - Case 4). The genetic analysis (clinical exome sequencing confirmed by Sanger sequencing) detected a large, previously not published deletion (NM_001001433.3(STX16):c.393+ 557 792 + 364del) in the STX16 gene (chr20:57243567$57,246,544$ in GRCh37 or chr20:58668511-58,671,488 in GRCh38). This alteration was also indicated as pathogenic in ClinVar database (VCV000978043.1) submitted by Undiagnosed Diseases Network, NIH in 2020. The patient received cholecalciferol and calcium supplementation. The proband has an asymptomatic sister whose head CT scan revealed cerebral calcification identical to her brother and the same mutation was also found. (The rest of the family refused to undergo a detailed medical examination.) (Supplementary file 2).

\section{Case 5 - Infiltration of the parathyroid gland}

The 34-year-old female patient was admitted due to progressive speech disorder, gait disturbance, and intermittent blurred vision in the left eye. Based on heteroanamnestic data, it was hard to express herself for half a year and counting problems were reported as well. Concurrently, she presented forgetfulness, emotional lability, lack of motivation, and clumsiness in her hands as well. Regarding the previous medical history, antecedent previous syphilis infection should be noted (no documentation was available). In an earlier laboratory study of the patient, anti-dsDNA antibody level was significantly elevated $(79 \mathrm{U} / \mathrm{ml})$, however, the level of antinuclear antibodies was normal. The patient had two miscarriages. The neurological phenotype was dominated by cerebellar symptoms, dysarthria, dysphagia, gait-activated dystonia and emotional instability (Supplementary video 5). The endocrine laboratory tests showed alteration compatible with the diagnosis of normocalcemic hypoparathyroidism (Table 3). The result of the routine EEG was normal. The neuropsychological assessment revealed significant cognitive involvement (ACE: 61/ 100 points) as well as impairment of language functions and abnormalities in retrograde memory. Head CT scan of the patient showed extensive calcification in the cerebellum, pons, basal ganglia, and subcortical regions (Fig. 1 - Case 5). No abnormality was demonstrated in thyroid ultrasound. A detailed dermatological examination revealed no abnormality suggestive of systemic lupus erythematosus. The performed whole exome sequencing did not identify any known or potential genetic abnormality underlying the clinical phenotype. Given that normocalcemic hypoparathyroidism may be due to a decreased reserve capacity of the parathyroid gland (Cusano et al. 2013), we considered the infiltration of the parathyroid gland by syphilis as an etiological factor, however, the possibility of neurolupus cannot be ruled out with absolute certainty (Andres et al. 2009). The patient required the initiation of tiapride and pyridostigmine therapies for progressive chorea and dysphagia. Tiapride resulted in a significant improvement of chorea.

\section{Case 6 - Secondary hypoparathyroidism}

The 72-year-old female patient was admitted to our department due to a temporary motor aphasia. After admission, the speech disorder was no longer observed, however, four limb hypotonia as well as cerebellar alterations (disturbance of alternating movements, intentional tremor, ataxic gait) and bilateral upper limb postural tremor were detected (Supplementary video 6). Regarding her previous medical history, total thyroidectomy due to follicular adenoma (oncocytic type; histological specimens also included the parathyroid glands) should be highlighted. The laboratory test abnormalities were consistent with hypoparathyroidism 
(Table 3). The routine electroencephalography was negative. Regarding cognitive alterations, mild impairment of executive functions and verbal fluency was found. The performed head CT scan showed extensive deposition of the calcium bilaterally in the basal ganglia and cortical regions (Fig. 1 - Case 6). Secondary (postthyroidectomy) hypoparathyroidism was considered in the background of symptoms of the patient. The patient was treated with cholecalciferol and calcium supplementation.

\section{Discussion}

As the scientific literature expands, identifying an etiology underlying cerebral calcification is a real diagnostic challenge, especially in the adult care. Occasionally, a definitive diagnosis can be made by analyzing only clinical symptoms or radiological abnormalities. However, in most cases, extensive clinical and laboratory studies are needed to find the diagnosis. Investigations should focus on potentially treatable etiologies, most often due to endocrine causes. Nevertheless, the identification of genetically determined diseases is essential mainly in terms of future clinical trials based on targeting the identified genetic alterations. The main goal of our research was to compare the clinical, laboratory and radiological characteristics of six patients identified with extensive cerebral calcification. Four hereditary and two non-hereditary etiologies were found associated with brain calcification.

In case $1(\mathrm{t}(\mathrm{X} ; 11))$, we identified a novel, previously not reported unbalanced chromosomal translocation (46,XY,der(11)t(X;11)(p21.1;q14.2)[152]/46,XY[48]) with unknown significance. The clinical symptoms correlated with the head CT pictures, namely, dysphagia could be explained by brainstem involvement, ataxia by cerebellar involvement. The laboratory examination of endocrine parameters of our patient did not contain any relevant pathological abnormalities similarly to other hereditary etiologies (Bonazza et al. 2011). Despite, the lack of specific complaints (e.g. headache $P D G F B$ ) and signs (e.g. parkinsonism - SLC20A2; seizure endocrine disorder) (Batla et al. 2017; Nicolas et al. 2013a, b) we made clinical exome sequencing, which indicated a deletion in chromosome 11, which prompted aCGH analyses. Regarding the pathogenicity of the genetic abnormality found in our patient, it was important to exclude other hereditary causes with high certainty. Therefore, we examined all the genetic alterations associated with cerebral calcification reported in the scientific literature (single nucleotide variations, deletions and duplications), but no pathogenic alteration was found (Batla et al. 2017; Tadic et al. 2015). The performed aCGH test detected a novel unbalanced translocation between chromosomes $\mathrm{X}$ and 11 in mosaic form and it was confirmed by FISH and MLPA analyses as well. This difference was not found in the offsprings (non-germline). The mechanism leading to this genetic alteration is still unknown. The disease may be caused by an increase in the dosage of gene products formed in connection with the partial duplication of the pseudoautosomal region of the short arm of chromosome $\mathrm{X}$ or a decrease in the dosage of gene products in the partially deleted region of the long arm of chromosome 11. However, the pathogenicity of the alteration cannot be clearly stated, further studies/case reports are needed to clarify this question. Genes affected by this translocation have not been clearly associated with cerebral calcification to date. The interpretation of the genetic abnormality observed in the patient is further complicated by the fact that the genetic abnormality was found only in the blood and not in the sample taken from the oral cavity. We have no knowledge of whether the genetic abnormality is present in other tissues (e.g. in the central nervous system). Consequently, it is very difficult to give a genotype-phenotype correlation, as it can be very different depending on the tissue-specific distribution. Cases 2 and 3, although the genetic mutation identified in the background involved the same gene (SLC20A2), the clinical picture was only partially matched. Although parkinsonism was observed in both cases (consistent with the literature data (Batla et al. 2017)), choreiform symptoms predominated in Case 2 , whereas cerebellar symptoms dominated in Case 3. A detailed laboratory examination did not show significant difference between the cases. Interestingly, the pontine calcification (observed in Case 1, 4, 5) was not detected in our two SLC20A2 cases, in line with the literature (Nicolas et al. 2013a, b); Chelban et al. (2020) reported that pontin calcification on head CT may refer to MYORG mutation. These two cases point out that involvement of the same gene, partly depending on the different site of mutation, may also have different phenotypes. The clinical picture of Case 4 was dominated by cerebellar involvement partially consistent with the head CT picture. The laboratory results showed alterations consistent with secondary hyperparathyroidism. This case is a good presentation of the clinical situation where, although there is an alteration in endocrine laboratory parameters, hereditary etiology still prevails (STX16). Although the STX16 deletion detected in our case affected exons 5-7, the clinical and laboratory picture (high PTH level, low calcium level, low or normal TSH level, absence of Albright osteodystrophy) was consistent with the findings observed in different mutations described previously (3 kb incl. ex. 4-6; $24.591 \mathrm{~kb}$ incl. ex. 2-8 (g.57235162$57259753 \mathrm{del}) ; 4.4 \mathrm{~kb}$ incl. ex. 2-4). Interestingly, a case with a more complex phenotype was described in the ClinVar database, in which the same genetic difference was identified as in our case (NM 001001433.3(STX16):c.393 + $557792+$ 364del - sleep apnea; short nasal bridge; overgrowth; obesity; exotropia; eczema; Arnold-Chiari malformation; 2-3 toe syndactyly) (Bastepe et al. 2003; Elli et al. 2014; Laspa et al. 2004; Linglart et al. 2005; Mantovani et al. 2007). The explanation for this could be that there is a second unidentified 
pathogenic alteration which could be resposible for these non STX16 related phenotypes, while the development of the cerebral calcification in later years could not be ruled out.

The fifth case illustrates the difficult clinical situation where, although endocrine abnormalities can be identified, they cannot be clearly associated with any known hereditary or non-hereditary disease (Ramos et al., 2017). The young age of the patient and extensive cerebral calcification would be primarily in favor of hereditary etiology, however, the change in parathyroid hormone levels observed may be related to the pregnancy and the anamnestic syphilis and the elevated antidsDNA antibody level raise the possibility of a secondary etiology. Deeper laboratory (e.g. autoimmune, serology) and genetic analysis (whole genome sequencing) could be a forward step in resolving the case with higher certainty, but the necessity of the even more detailed laboratory evaluation is questionable and forms a limitation of our study. In contrast, the sixth case presents a very common and easily diagnosable etiology. Unfortunately, in clinical practice, follow-up and adequate treatment (calcium and hydroxy-vitamin D supplementation) of patients with permanent hypocalcemia after thyroidectomy is often missing (Miccoli et al. 2012; Petrarca et al. 2017).

The aim of the present study was to describe and clinically characterize and compare five different etiologies associated with cerebral calcification. We conclude that accurate clinical, radiological and laboratory analyses lead to diagnosis in most cases. Furthermore, in well-selected cases, aCGH method can provide more complex information about the potentially relevant genetic alterations.

Supplementary Information The online version contains supplementary material available at https://oi.org/10.1007/s11011-021-00790-9.

Authors' contributions AS and DZ examined the patients and wrote the manuscript. VLN and NSZ performed the neuropsychological examination of the patients. Genetic tests and consultations were performed by AU, ZM, EH, IB and TK. PK and CSB had important recommendations to the manuscript. LSZ, ML and BB provided essential assistance in patient involvement and investigation.

Funding GINOP-2.3.2-15-2 grant (TK and ZM) provided by the National Research, Development and Innovation Office (Hungary). Hungarian Brain Research Program [2017-1.2.1-NKP-2017-00002 NAP VI/4] (PK).

Data availability The datasets used and/or analyzed in the current study are available in this paper.

\section{Declarations}

Ethics approval Written informed consent was obtained from all individual participants included in the study. Additional informed consent was obtained from all individual participants for whom identifying information is included in this article (Regional Human Biomedical Research Ethics Committee of the University of Szeged registration numbers are
150/2014. and 44/2016., respectively). All procedures performed in this study involving human participants were in accordance with the ethical standards of the Regional Human Biomedical Research Ethics Committee of the University of Szeged and with the 1964 Helsinki declaration and its later amendments or comparable ethical standards.

Consent to participate Not applicable.

Consent for publication Not applicable.

Conflicts of interest/competing interests The authors declare that they have no competing/conflict of interests.

\section{References}

Andres RH, Schroth G, Remonda L (2009) Extensive cerebral calcification in a patient with systemic lupus erythematosus. BMJ case reports 2009:bcr2007125393. https://doi.org/10.1136/bcr.2007. 125393

Bastepe M, Fröhlich LF, Hendy GN, Indridason OS, Josse RG, Koshiyama H, Körkkö J, Nakamoto JM, Rosenbloom AL, Slyper AH, Sugimoto T, Tsatsoulis A, Crawford JD, Jüppner H (2003) Autosomal dominant pseudohypoparathyroidism type $\mathrm{Ib}$ is associated with a heterozygous microdeletion that likely disrupts a putative imprinting control element of GNAS. J Clin Invest 112:1255-1263. https://doi.org/10.1172/JCI19159

Batla A, Tai XY, Schottlaender L, Erro R, Balint B, Bhatia KP (2017) Deconstructing Fahr's disease/syndrome of brain calcification in the era of new genes. Parkinsonism Relat Disord 37:1-10. https://doi. org/10.1016/j.parkreldis.2016.12.024

Bauer M, Rahat D, Zisman E, Tabach Y, Lossos A, Meiner V, Arkadir D (2019) MYORG mutations: a major cause of recessive primary familial brain calcification. Curr Neurol Neurosci Rep 19:70. https:// doi.org/10.1007/s11910-019-0986-Z

Bonazza S, Morgia CL, Martinelli P, Capellari S (2011) Strio-pallidodentate calcinosis: a diagnostic approach in adult patients. Neurol Sci 32:537-545. https://doi.org/10.1007/s10072-011-0514-7

Cen Z, Chen Y, Chen S, Wang H, Yang D, Zhang H, Wu H, Wang L, Tang S, Ye J, Shen J, Wang H, Fu F, Chen X, Xie F, Liu P, Xu X, Cao J, Cai P, Pan Q, Li J, Yang W, Shan PF, Li Y, Liu JY, Zhang B, Luo W (2020) Biallelic loss-of-function mutations in JAM2 cause primary familial brain calcification. Brain 143:491-502. https://doi. org/10.1093/brain/awz392

Chelban V, Carecchio M, Rea G, Bowirrat A, Kirmani S, Magistrelli L, Efthymiou S, Schottlaender L, Vandrovcova J, Salpietro V, Salsano E, Pareyson D, Chiapparini L, Jan F, Ibrahim S, Khan F, Qarnain Z, Groppa S, Bajaj N, Balint B, Bhatia KP, Lees A, Morrison PJ, Wood NW, Garavaglia B, Houlden H (2020) MYORG-related disease is associated with central pontine calcifications and atypical parkinsonism. Neurol Genet 6:e399. https://doi.org/10.1212/NXG. 0000000000000399

Chen WJ, Yao XP, Zhang QJ, Ni W, He J, Li HF, Liu XY, Zhao GX, Murong SX, Wang N, Wu ZY (2013) Novel SLC20A2 mutations identified in southern Chinese patients with idiopathic basal ganglia calcification. Gene 529:159-162. https://doi.org/10.1016/j.gene. 2013.07.071

Cusano NE, Maalouf NM, Wang PY, Zhang C, Cremers SC, Haney EM, Bauer DC, Orwoll ES, Bilezikian JP (2013) Normocalcemic hyperparathyroidism and hypoparathyroidism in two community-based nonreferral populations. J Clin Endocrinol Metab 98:2734-2741. https://doi.org/10.1210/jc.2013-1300

De Oliveira MF, Silva EBE, de Oliveira JRM (2013) Prevalence of brain calcifications in a Brazilian cohort: a retrospective study in radiology 
services. Dement Neuropsychol 7:210-215. https://doi.org/10.1590/ S1980-57642013DN70200012

Donzuso G, Mostile G, Nicoletti A, Zappia M (2019) Basal ganglia calcifications (Fahr's syndrome): related conditions and clinical features. Neurol Sci 40:2251-2263. https://doi.org/10.1007/s10072019-03998-x

Elli FM, Sanctis LD, Peverelli E, Bordogna P, Pivetta B, Miolo G, BeckPeccoz P, Spada A, Mantovani G (2014) Autosomal dominant pseudohypoparathyroidism type Ib: a novel inherited deletion ablating STX16 causes loss of imprinting at the a/B DMR. J Clin Endocrinol Metab 99:E724-E728. https://doi.org/10.1210/jc.20133704

Keller A, Westenberger A, Sobrido MJ, García-Murias M, Domingo A, Sears RL, Lemos RR, Ordoñez-Ugalde A, Nicolas G, da Cunha JEG, Rushing EJ, Hugelshofer M, Wurnig MC, Kaech A, Reimann R, Lohmann K, Dobričić V, Carracedo A, Petrović I, Miyasaki JM, Abakumova I, Mäe MA, Raschperger E, Zatz M, Zschiedrich K, Klepper J, Spiteri E, Prieto JM, Navas I, Preuss M, Dering C, Janković M, Paucar M, Svenningsson P, Saliminejad K, Khorshid HRK, Novaković I, Aguzzi A, Boss A, Le Ber I, Defer G, Hannequin D, Kostić VS, Campion D, Geschwind DH, Coppola G, Betsholtz C, Klein C, Oliveira JRM (2013) Mutations in the gene encoding PDGF-B cause brain calcifications in humans and mice. Nat Genet 45:1077-1082. https://doi.org/10.1038/ng.2723

Kıroğlu Y, Callı C, Karabulut N, Oncel C (2010) Intracranial calcifications on CT. Diagn Interv Radiol 16:263-269. https://doi.org/10. 4261/1305-3825.DIR.2626-09.1

Kostić VS, Petrović IN (2017) Brain calcification and movement disorders. Curr Neurol Neurosci Rep 17:2. https://doi.org/10.1007/ s11910-017-0710-9

Laspa E, Bastepe M, Jüppner H, Tsatsoulis A (2004) Phenotypic and molecular genetic aspects of pseudohypoparathyroidism type $\mathrm{Ib}$ in a Greek kindred: evidence for enhanced uric acid excretion due to parathyroid hormone resistance. J Clin Endocrinol Metab 89:59425947. https://doi.org/10.1210/jc.2004-0249

Legati A, Giovannini D, Nicolas G, López-Sánchez U, Quintáns B, Oliveira JRM, Sears RL, Ramos EM, Spiteri E, Sobrido MJ, Carracedo Á, Castro-Fernández C, Cubizolle S, Fogel BL, Goizet C, Jen JC, Kirdlarp S, Lang AE, Miedzybrodzka Z, Mitarnun W, Paucar M, Paulson H, Pariente J, Richard AC, Salins NS, Simpson SA, Striano P, Svenningsson P, Tison F, Unni VK, Vanakker O, Wessels MW, Wetchaphanphesat S, Yang M, Boller F, Campion D, Hannequin D, Sitbon M, Geschwind DH, Battini JL, Coppola G (2015) Mutations in XPR1 cause primary familial brain calcification associated with altered phosphate export. Nat Genet 47:579-581. https://doi.org/10.1038/ng.3289

Linglart A, Gensure RC, Olney RC, Jüppner H, Bastepe M (2005) A novel STX16 deletion in autosomal dominant pseudohypoparathyroidism type $\mathrm{Ib}$ redefines the boundaries of a cis-acting imprinting control element of GNAS. Am J Hum Genet 76:804-814. https://doi.org/10.1086/429932

Mantovani G, Bondioni S, Linglart A, Maghnie M, Cisternino M, Corbetta S, Lania AG, Beck-Peccoz P, Spada A (2007) Genetic analysis and evaluation of resistance to thyrotropin and growth hormone-releasing hormone in pseudohypoparathyroidism type Ib. J Clin Endocrinol Metab 92:3738-3742. https://doi.org/10.1210/jc. 2007-0869

Manyam BV (2005) What is and what is not 'Fahr's disease'. Parkinsonism Relat Disord 11:73-80. https://doi.org/10.1016/j. parkreldis.2004.12.001

Miccoli P, Minuto MN, Miccoli M (2012) Incidence of morbidity following thyroid surgery. Thyroid surgery: preventing and managing complications. John Wiley \& Sons, Ltd 2012:6-7
Nicolas G, Pottier C, Charbonnier C, Guyant-Maréchal L, Le Ber I, Pariente J, Labauge P, Ayrignac X, Defebvre L, Maltête D, Martinaud O, Lefaucheur R, Guillin O, Wallon D, Chaumette B, Rondepierre P, Derache N, Fromager G, Schaeffer S, Krystkowiak P, Verny C, Jurici S, Sauvée M, Vérin M, Lebouvier T, Rouaud O, Thauvin-Robinet C, Rousseau S, Rovelet-Lecrux A, Frebourg T, Campion D, Hannequin D, French IBGC Study Group (2013a) Phenotypic spectrum of probable and genetically-confirmed idiopathic basal ganglia calcification. Brain 136:3395-3407. https:// doi.org/10.1093/brain/awt255

Nicolas G, Pottier C, Maltête D, Coutant S, Rovelet-Lecrux A, Legallic S, Rousseau S, Vaschalde Y, Guyant-Maréchal L, Augustin J, Martinaud O, Defebvre L, Krystkowiak P, Pariente J, Clanet M, Labauge P, Ayrignac X, Lefaucheur R, Le Ber I, Frébourg T, Hannequin D, Campion D (2013b) Mutation of the PDGFRB gene as a cause of idiopathic basal ganglia calcification. Neurology 80 : 181-187. https://doi.org/10.1212/WNL.0b013e31827ccf34

Petrarca M, Scipioni R, Di Giosia P, Giorgini P, Ferri C (2017) A case of brain calcifications in postsurgical hypoparathyroidism. Intern Emerg Med 12:113-115. https://doi.org/10.1007/s11739-016$1430-\mathrm{x}$

Ramos EM, Oliveira J, Sobrido MJ, Coppola G (2017) Primary familial brain calcification. In: Adam MP, Ardinger HH, Pagon RA, et al. (eds) GeneReviews ${ }^{\circledR}$ [internet]. Seattle (WA): University of Washington, Seattle, 1993-2021. Available from: https://www. ncbi.nlm.nih.gov/books/NBK1421/

Saade C, Najem E, Asmar K, Salman R, Achkar BE, Naffaa L (2019) Intracranial calcifications on CT: an updated review. J Radiol Case Rep 13:1-18. https://doi.org/10.3941/jrcr.v13i8.3633

Saleem S, Aslam HM, Anwar M, Anwar S, Saleem M, Saleem A, Rehmani MAK (2013) Fahr's syndrome: literature review of current evidence. Orphanet J Rare Dis 8:156. https://doi.org/10.1186/1750$1172-8-156$

Savino E, Soavi C, Capatti E, Borrelli M, Vigna GB, Passaro A, Zuliani G (2016) Bilateral strio-pallido-dentate calcinosis (Fahr's disease): report of seven cases and revision of literature. BMC Neurol 16:165. https://doi.org/10.1186/s12883-016-0693-1

Taborda KNN, Wilches C, Manrique A (2017) A diagnostic algorithm for patients with intracranial calcifications. Rev Colomb Radiol 28: 4732-4739

Tadic V, Westenberger A, Domingo A, Alvarez-Fischer D, Klein C, Kasten M (2015) Primary familial brain calcification with known gene mutations: a systematic review and challenges of phenotypic characterization. JAMA Neurol 72:460-467. https://doi.org/10. 1001/jamaneurol.2014.3889

Wang C, Li Y, Shi L, Ren J, Patti M, Wang T, de Oliveira JRM, Sobrido MJ, Quintáns B, Baquero M, Cui X, Zhang XY, Wang L, Xu H, Wang J, Yao J, Dai X, Liu J, Zhang L, Ma H, Gao Y, Ma X, Feng S, Liu M, Wang QK, Forster IC, Zhang X, Liu JY (2012) Mutations in SLC20A2 link familial idiopathic basal ganglia calcification with phosphate homeostasis. Nat Genet 44:254-256. https://doi.org/10. 1038/ng. 1077

Westenberger A, Balck A, Klein C (2019) Primary familial brain calcifications: genetic and clinical update. Curr Opin Neurol 32:571-578. https://doi.org/10.1097/WCO.0000000000000712

Yamada M, Asano T, Okamoto K, Hayashi Y, Kanematsu M, Hoshi H, Akaiwa Y, Shimohata T, Nishizawa M, Inuzuka T, Hozumi I (2013) High frequency of calcification in basal ganglia on brain computed tomography images in Japanese older adults. Geriatr Gerontol Int 13:706-710. https://doi.org/10.1111/ggi.12004

Publisher's note Springer Nature remains neutral with regard to jurisdictional claims in published maps and institutional affiliations. 